[Agr. Biol. Chem., Vol. 30, No. 4, p. 359 363, 1966]

\title{
A General Assay Method for Nucleotide Pyrophosphorylases
}

\author{
By Yuji Nagano, Hirotoshi Samejima and Shukuo Kinoshita \\ Tokyo Research Laboratory, Kyowa Hakko Kogyo Co., Ltd., Tokyo \\ Received September 28, 1965
}

\begin{abstract}
A general assay method for nucleotide pyrophosphorylases has been investigated. The principle of the method is based on the measurement of consumption rate of 5-phosphoribosylpyrophosphate (PRPP) during the enzyme reaction. In the method, an enzyme preparation for sample was incubated in a reaction mixture containing a purine or pyrimidine base and PRPP for a certain time, and the amounts of PRPP before and after the reaction were determined. The amount of PRPP was determined by an enzymatic method using orotidine-5'-monophosphate (5'-OMP) pyrophosphorylase and 5'-OMP decarboxylase. Nucleotide pyrophosphorylase activity corresponding to each purine or pyrimidine base was determined from the amount of PRPP consumed per unit time.

The present method is generally applicable for determining activities of any kind of nucleotide pyrophosphorylases, and does not need any tedious separation procedure in all cases. Therefore, comparing with the conventional assay methods for nucleotide pyrophosphorylase activities, this method can be said to be much simpler and reliable. As an application of the present method, activities of several nucleotide pyrophosphorylases in Micrococcus glutamicus have been determined.
\end{abstract}

\section{INTRODUCTION}

In a previous paper, ${ }^{1}$ an assay method for orotidine-5'-monophosphate $\left(5^{\prime}\right.$-OMP) pyrophosphorylase using spectrophotometry was reported. For the assay of various other nucleotide pyrophosphorylases, individually different assay methods which are suitable for each of them have been employed. Besides them, as general assay method for nucleotide pyrophosphorylase, two methods have been reported. ${ }^{2)}$ In the first method, ${ }^{14} \mathrm{C}$-labeled bases were used. Nncleotide formed from each ${ }^{14} \mathrm{C}$-labeled base by the enzyme reaction was separated by ion-exchange resin chromatography or paper chromatography, and radioactivity in the nucleotide fraction was measured. Thus, from the amount of nucleotide formed per unit time, enzyme activity was determined. Though the method is quite

1) Y. Nagano, K. Inuzuka, H. Samejima and S. Kinoshita, This Journal, 30, 99 (1966).

2) J.G. Flaks, "Methods in Enzymology", Vol. 6, Academic Press Inc. Ltd., p. 136 sensitive, it is rather time-consuming, and also special caution must be taken in the fractionation procedure of nucleotide formed depending on individual base used. In the second method, ${ }^{3)} 5^{\prime}$-phosphoribosylpyrophosphate (PRPP) was determined by the method of orcinol reaction before and after the enzyme reaction. Enzyme preparation was incubated in a reaction mixture containing PRPP of known concentration. After a given time interval, nucleotide which was formed from PRPP and base was removed from the reaction mixture by active carbon treatment, and residual PRPP in the reaction mixture was determined. Nucleotide formed was estimated from the amount of PRPP consumed during the enzyme reaction. Enzyme activity was then calculated from the nucleotide formed per unit time. The method is less sensitive than the first method using ${ }^{14} \mathrm{C}$-labeled bases. Also, recovery test showed that the 3) G.P. Kalle and J.S. Gots, Biochim. et Biophys. Acta, 53, 166 (1961). 
method was less reliable because the method involved the active carbon treatment.

Enzymatic determination of PRPP was reported in a previous paper. ${ }^{1)}$ This assay method was a specific microdetermination for PRPP. The present paper deals with investigation on a general assay method for nucleotide pyrophosphorylases, in which the enzymatic determination of PRPP was involved as a principal part. In the general assay method, an enzyme preparation for sample was incubated in a reaction mixture containing PRPP and pyrimidine or purine base, and the reaction proceeded as in the following equation:

$$
\text { Base + PRPP } \longrightarrow \text { Nucleotide + PPi }
$$

Then, after a certain time of incubation, PRPP in the reaction mixture was determined by the enzymatic method. Enzyme activity was represented as the amounts of PRPP consumed per unit time.

The present method is more versatile because it is generally applicable for any nucleotide pyrophosphorylase which is corresponding to each of bases. That is, the method is much simpler and reliable than the previous methods which need distinct fractionation pretreatments according to varieties of bases as described above. Also, PRPP in the reaction mixture containing base, nucleotide and pyrophosphate was determined by an enzymatic method without any pretreatment, such as carbon treatment. So, these have made the present method more sensitive and reliable. Using the present assay method for nucleotide pyrophosphorylases, distribution of nucleotide pyrophosphorylases in Micrococcus glutamicus was investigated, and the results are also given in the present paper.

\section{MATERIALS AND METHODS}

Enzyme solution. Cultivation of $M$. glutamicus and preparation of cell-free extract were carried out as shown in the previous paper. ${ }^{4}$ Acetone-dried

4) X. Nagano, H. Samejima and S. Kinoshita, This Journal, 30, 83 (1966). cells were extracted with Tris buffer, and the cellfree extract was dialyzed against the same buffer at $0^{\circ} \mathrm{C}$ for 24 hours. The dialyzate was used as the enzyme solution.

Chemicals. Orotic acid was obtained from Kyowa Hakko Co., Tokyo, and PRPP from Sigma Chemical Co., St. Louis, Missouri. All bases were obtained from the Nutritional Biochemicals Corp., U.S.A.

\section{Assay method for nucleotide pyrophosphory.} lase.

1) Reagents

$10 \mathrm{mM}$ Tris buffer $(\mathrm{pH} 8.0)$

$10 \mathrm{mM} \mathrm{MgCl}_{2}$

$1.0 \mathrm{mM}$ PRPP

$0.5 \mathrm{~mm}$ Each of various bases

Enzyme solution (for example)

2) Procedure

Reaction mixture contained one $\mathrm{ml}$ each of Tris buffer, $\mathrm{MgCl}_{2}$, PRPP, base and enzyme solution. Incubation was carried out at $30^{\circ} \mathrm{C}$ for 20 minutes. After incubation, the reaction mixture was heated in a boiling water bath for 2 minutes. Precipitate appeared was removed by centrifugation. As the control, the reaction mixture without the enzyme solution was incubated as described above. And, as the blank, the reaction mixture from which both base and PRPP were omitted was treated in the same way. PRPP in the supernatant fluid was determined by an enzymatic method as described in the previous paper. ${ }^{1}$

3) Calculation

The enzyme activity was represented as the difference in the amount of PRPP in the control tube and the sample tube after the reaction. There was a linear relationship between enzyme activity and the consumed amount of PRPP in concentration of PRPP ranging from zero to $150 \mathrm{~m} \mu \mathrm{M}$. Therefore, enzyme solution for sample was diluted to be suitable to the condition.

\section{RESUL'TS}

On the conditions for the general assay method of nucleotide pyrophosphorylases.

The general assay method of various nucleotide pyrophosphorylases was carried out almost in the same way as described in the assay method of $5^{\prime}$-OMP pyrophosphorylase." However, in the present assay method, there was an exception that the amount of PRPP was determined just after the enzyme reaction 
and the enzyme activity was represented by the difference in the amounts of PRPP before and after the reaction. Therefore, in the present method, it was desirable that the amount of PRPP in the reaction mixture should be in an appropriate concentration range for the subsequent enzymatic determination of PRPP. For this reason, the initial concentration of PRPP in the reaction mixture was chosen to be $1.0 \mu \mathrm{mole} / \mathrm{ml}$.

Using such reaction mixture as described above, appropriate reaction time and enzyme concentration were examined. In a case when guanine was used as a base, time course of nucleotide pyrophosphorylase reaction was examined. As shown in Fig. 1, an initial linear part of the reaction curve was observed at least for the first 20 minutes. Therefore, the enzyme activity was defined as the amount of PRPP consumed for the first 20 minutes of the reaction.

Then, in order to decide measurable range of enzyme concentration, the relationship between enzyme concentration and enzyme activity (represented by the amount of PRPP

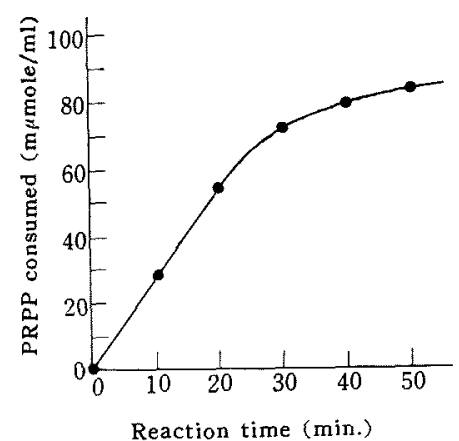

FIG. 1. Time Course of Enzyme Reaction.

Reaction mixture contained one $\mathrm{ml}$ each of $10 \mathrm{~mm}$ Tris buffer ( $\mathrm{pH} 8.0$ ), $10 \mathrm{~mm} \mathrm{MgCl} 21.0 \mathrm{~mm}$ PRPP, $0.5 \mathrm{~mm}$ guanine and enzyme solution. After incubation at $30^{\circ} \mathrm{C}$ for a certain time, the enzyme reaction was stopped by placing the test tube in a boiling water bath for 2 minutes. Insoluble material was removed by centrifugation, and PRPP in the supernatant was measured. The removed PRPP was determined by subtracting PRPP present in the reaction mixture after incubation from PRPP present in an initial reaction mixture. consumed) was examined. The experimental results using the enzyme solution of various concentrations are given in Fig. 2. There was a linear relationship between enzyme concentration and enzyme activity when the enzyme activity was less than $150 \mathrm{~m} \mu \mathrm{mole} / \mathrm{ml}$.



FIG. 2. Relation between Enzyme Concentration and Enzyme Activity.

Reaction mixture was identical to that in Fig. 1 , except that concentrated enzyme solution was used in various dilutions. Enzyme activity was represented as the consumed a mount of PRPP for 20 minutes.

Distribution of Nucleotide Pyrophosphorylases in Micrococcus glutamicus.

As an application of the present general assay method, activities of various nucleotide pyrophosphorylases in $M$. glutamicus were determined. Total twenty-seven bases, involving nine pyrimidine bases and eighteen purine bases, were examined. The results are given in Table I. Among the bases examined, five pyrimidine bases such as uracil, 5-nitrouracil, orotic acid, and 5-fluoroorotic acid, and also six purine bases such as guanine, 6-thioguanine, 6-mercaptoguanine, xanthine, hypoxanthine, and 2,6-diaminopurine were found to be active. The enzyme activities corresponding to uracil, orotic acid, hypoxanthine and guanine were especially high. However, only from these experimental results, it is difficult to say whether such nucleotide pyrophosphorylase activities which are active to these bases are derived from a single enzyme or different enzymes. 
Table I. NuCleotide Pyrophosphorylae IN Micrococcus glutamicus

\begin{tabular}{lr}
\multicolumn{1}{c}{$\begin{array}{c}\text { Substrate } \\
\text { Pyrimidine bases }\end{array}$} & $\begin{array}{r}\text { PRP removed } \\
(\mathrm{m} \mu \mathrm{mol} / \mathrm{ml})\end{array}$ \\
Uracil & 110 \\
5-Nitrouracil & 12 \\
Thiouracil & 0 \\
Orotic acid & 100 \\
5-Fluoroorotic acid & 60 \\
5-Methylorotic acid & 0 \\
Thymine & 0 \\
Cytosine & 0 \\
Isocytosine & 0 \\
Purine bases & \\
Purine & 0 \\
Guanine & 120 \\
Adenine & 0 \\
Xanthine & 54 \\
Hypoxanthine & 120 \\
8-Azaguanine & 0 \\
8-Azaadenine & 0 \\
8-Azaxanthine & 0 \\
8-Azahypoxanthine & 0 \\
2-Thioadenine & 0 \\
6-Thioguanine & 0 \\
6-Mercatoguanine & 0 \\
8-Chloroxanthine & 0 \\
2,8-Dithio-6-oxypurine & 0 \\
6-Mercaptopurine & 0 \\
2,6-Diaminopurine & 0 \\
Uric acid & 0 \\
6-Methylmercaptopurine & 0 \\
& 0 \\
&
\end{tabular}

\section{DISCUSSION}

In the present general assay method of nucleotide pyrophosphorylases, enzyme activities were determined from the amount of PRPP which was consumed during the enzyme reaction shown in the following equation (1). The amounts of PRPP were also determined by a specific microdetermination using OMP pyrophosphorylase extracted from $M$. glutamicus, and such reaction is shown in the following equation (2).

$$
\text { Base }+ \text { PRPP } \underset{\text { nucleotide pyrophosphorylase }}{\rightleftarrows}
$$

$$
\begin{gathered}
\mathrm{PRPP}+\text { Orotic acid } \longrightarrow \mathrm{UMP}+\mathrm{CO}_{2}+\mathrm{PPi}(2) \\
\text { OMP pyrophosphorylase from } \\
\text { M. glutamicus }
\end{gathered}
$$

Then, even though there are nucleotide, base and pyrophosphate in the reaction mixture as shown in the equation (1), they don't interfere the assay of PRPP because PRPP is determined by a specific enzyme reaction. Therefore, no preliminary separation procedures such as chromatography, carbon treatment and so on are necessary in the present method. This has made the present method much simple, time-saving and accurate. Thus, the method is advantageous over conventional assay methods of nucleotide pyrophosphorylase activities because it can be generally applicable for almost all kinds of nucleotide pyrophosphorylases. In the present paper, this method was successfully applied for the determination of activities of various nucleotide pyrophosphorylases in $M$. glutamicus.

If this assay method is applied for enzyme preparations obtained from other souces than M. glutamicus, characteristics of other nucleotide pyrophosphorylases than OMP pyrophos* phorylase must be taken account of especially in the reaction of the equation (2). However, this problem might be solved by the following two reasons:

(1) Optimum pH of OMP pyrophosphorylase is $\mathrm{pH}$ 9.0. While, optimum $\mathrm{pH}$ values for other nucleotide pyrophosphorylases have been reported to be $8.0 .^{2)}$ Therefore, under the condition of PRPP determintion at $\mathrm{pH}$ 9.0, activities of other nucleotide pyrophosphorylases must be depressed. (2) Even if whole amount of a certain base is remained intact in the reaction of the equation (1), its concentration is only one fifth of that of orotic acid added in the reaction mixture for PRPP determination. Under such condition, activity of other nucleotide pyrophosphorylases corresponding to the base must be remarkably depressed.

(1) Thus, influence of other nucleotide pyrophosphorylases than OMP pyrophosphorylase 
on the enzymtic determination of PRPP might be minimized in respect of $\mathrm{pH}$ and substrate concentration. Therefore, this general assay method of nucleotide pyrophosphorylase can be said to be applicable for any enzyme preparations from natural materials.

Flaks ${ }^{2)}$ classified nucleotide pyrophosphorylases into four different groups depending on their substrate specificity. Those are 1) AMP2) IMP-GMP- 3) OMP- and 4) UMP-pyrophosphorylase. Adopting his classification, from the experimental results of nucleotide pyrophosphorylase activities in $M$. glutamicus (see Table I) it can be said that GMP-IMP-, OMP -and UMP-pyrophosphorylases are present in $M$. glutamicus, but not AMP-pyrophosphorylase. Besides them, XMP pyrophosphorylase activity was also found in the enzyme preparation from $M$. glutamicus. Thus, it is assumed that various nucleotide pyrophosphorylase activites of $M$. glutamicus are not derived from single enzyme but from at least four different nucleotide pyrophosphorylases. Substrate specificities of OMP pyrophosphorylase for orotic acid analogues were not examined in case of M. glutamicus. However, in the enzyme preparation from brewer's dried yeast, Lieberman et al. ${ }^{5}$, Holmes ${ }^{6)}$ and Dahl et al. ${ }^{7)}$ have reported the enzyme to be active only for orotic acid and 5-fluoroorotic acid among several analogues of orotic acid.

Distribution of OMP pyrophosphorylase in cells of various bacteria is given in Table II. Nine typical strains of bacteria were used.

5) L. Lieberman, A. Kornberg and E.S. Simms, J. Biol. Chem. 215, 403 (1955).

6) W.L. Holmes, ibid., 223, 677 (1956).

7) J.L. Dahl, J. L. Way and R. E. Park, ibid., 234, 2998 (1959).
TABLE II. Distribution OF OROTIDINE-5'-PhOSPhate Pyrophosphorylase IN Bacteria

The fermentation medium consisted of glucose, $2.0 \%$; peptone, $1.0 \%$; meat extract, $0.5 \% ; \mathrm{NaCl}$, $0.25 \% ; \mathrm{MgSO}_{4} \cdot 7 \mathrm{H}_{2} \mathrm{O}, 0.025 \% ; \mathrm{K}_{2} \mathrm{HPO}_{4}, 0.1 \%$; yeast extract, $0.2 \% \mathrm{pH}$ of medium was adjusted to 7.0 with $\mathrm{NaOH}$. One loopful of bacterial cells from a slanted agar culture was inoculated to $200 \mathrm{ml}$ of sterilized fermentation medium in Erlenmeyer flask of $2 \mathrm{l}$, and the flask was shaken on a shaking device for 24 hours at $28^{\circ} \mathrm{C}$. The cells in the fermentation broth were harvested by centrifugation at $5,000 \times \mathrm{g}$ for 15 minutes, and washed twice with $200 \mathrm{ml}$ of $10 \mathrm{~mm}$ Tris buffer ( $\mathrm{pH} 8.0)$. Two grams of the wet cells were suspended in $20 \mathrm{ml}$ of Tris buffer of $\mathrm{pH} 8.0$, and sonicated in $10 \mathrm{KC}$ for 15 minutes. The sonicate was then centrifuged for 20 minutes at $10,000 \times \mathrm{g}$. Enzyme activity in the supernatant was determined by spectrophotometric method as described in the previous paper.1)

\begin{tabular}{lc}
\multicolumn{1}{c}{ Microorganisms } & $\begin{array}{c}\text { Enzyme Activity } \\
\text { (unit/ml) }\end{array}$ \\
Aerobacter aerogenes & 0.0 \\
Bacillus subtilis & 0.0 \\
Proteus vulgaris & 0.0 \\
Escherichia coli & 0.30 \\
Serratia marcescens & 0.0 \\
Micrococcus glutamicus & 1.48 \\
Micrococcus epidermidis & 0.80 \\
Pseudomonas aeruginosa & 2.50 \\
Pseudomonas ovalis & 1.60
\end{tabular}

The enzyme activity was determined by the spectrophotometric method described in the previous paper. ${ }^{1}$ As shown in Table II, potent activity of OMP of pyrophosphorylase was found especially in Micrococcus and Pseudomonas. It is considered that the similar tendency may be found with respect to other nucleotide pyrophosphorylases. 